\title{
Self-texturing of nitrogenated amorphous carbon thin films for electron field emission
}

\author{
S. R. P. Silva ${ }^{a}$ \\ Department of Electronic and Electrical Engineering, University of Surrey, Guildford, Surrey GU2 5XH, \\ United Kingdom
}

Gehan A. J. Amaratunga

Department of Electrical Engineering and Electronics, University of Liverpool, Liverpool L69 3BX, United Kingdom

J. R. Barnes

Department of Engineering, University of Cambridge, Trumpington Street, Cambridge CB2 1PZ, United Kingdom

(Received 6 June 1997; accepted for publication 14 July 1997)

\begin{abstract}
The electron field-emission process for nitrogenated amorphous carbon $(a-\mathrm{C}: \mathrm{H}: \mathrm{N})$ thin films deposited using a magnetically confined hydrocarbon plasma is examined. The morphology of the films obtained using an atomic force microscope is compared to the field-emission properties. Beyond a chemical composition of 14 at. \% nitrogen, the mirror smooth $a-\mathrm{C}: \mathrm{H}: \mathrm{N}$ films become self-texturing, and multiple "domelike" cathodes of nanometer scale are observed. The dimensions of these "domelike" cathodes varies with time, and after a 15 min deposition have dimensions of approximately $50 \mathrm{~nm}$ base diameter and $20 \mathrm{~nm}$ in height. When the electronic field emission of these textured films ( $\mathrm{N}$ content 15 at. \%) are measured, there is an enhancement in the emitted current density of $\sim 2$ orders of magnitude at an electric field of $20 \mathrm{~V} / \mu \mathrm{m}$, in comparison to the untextured films with a nitrogen content of 11 at. \%. (C) 1997 American Institute of Physics.
\end{abstract}

[S0003-6951(97)03337-8]

There is much interest in carbon based electron field emitters for display applications. ${ }^{1,2}$ Electron field emission from diamond, ${ }^{3,4}$ nitrogenated diamond, ${ }^{5}$ ceasiated diamond, ${ }^{6}$ and amorphous carbon, ${ }^{7,8}$ have been reported at moderately low electric fields. One of the major factors that have contributed to electron field emission at low fields is attributed to the low electron affinity of carbon films. ${ }^{9-11}$ Recent analysis of results have shown that space-chargeinduced band bending of the carbon films could be important in both amorphous carbon ${ }^{8,12,13}$ and diamond films ${ }^{6,14}$ contributing to enhanced field emission.

In this letter, we report the self-texturing $a-\mathrm{C}: \mathrm{H}: \mathrm{N}$ films that by virtue of their composition and texturing give rise to enhanced field emission with current densities $>10^{-4} \mathrm{~A} \mathrm{~cm}^{-2}$ at low electric fields $(<7 \mathrm{~V} / \mu \mathrm{m})$. The surfaces of the amorphous films have been examined using an atomic force microscope (AFM).

The nitrogenated amorphous carbon $(a-\mathrm{C}: \mathrm{H}: \mathrm{N})$ films were deposited using a magnetically enhanced parallel plate capacitively coupled plasma-enhanced chemical-vapor deposition (PECVD) system described in detail elsewhere. ${ }^{15,16} \mathrm{~A}$ hydrocarbon containing gas mixture of $\mathrm{CH}_{4} / \mathrm{He} / \mathrm{N}_{2}$ was dissociated at a rf power of $30 \mathrm{~W}$ to deposit $a-\mathrm{C}: \mathrm{H}: \mathrm{N}$ films on highly doped $(0.01-0.001 \Omega \mathrm{cm}) n$-Si substrates. The films were deposited on substrates held at room temperature, and the properties of the films can be found in the literature. ${ }^{16}$ Nitrogen in amorphous carbon films is shown to act at a weak donor and alters the joint density of states in the films. Field-emission measurements were carried out using a parallel plate configuration with the film being the cathode and an

${ }^{a)}$ Electronic mail: S.Silva@ee.surrey.ac.uk
ITO coated glass the anode placed $50 \mu \mathrm{m}$ from the cathode using glass fiber spacers. ${ }^{8,12}$ Measurements assume the films emit uniformly over the $1 \mathrm{~cm}^{2}$ substrates and were performed at a pressure better than $1 \times 10^{-6}$ Torr. The current density electric field $(J-E)$ characteristics are repeatable over periods of weeks and the films do not degrade with exposure to atmospheric conditions over this time period. Microscopy was performed in air using $\mathrm{Si}_{3} \mathrm{~N}_{4}$ cantilevers in a custom built optical deflection-type AFM.

The change in surface morphology that occurs when there is more than 14 at. \% nitrogen in the $a-\mathrm{C}: \mathrm{H}: \mathrm{N}$ films is illustrated in Fig. 1. All the films analyzed with nitrogen contents of less than 14 at. \% had smooth surfaces with minimum-to-maximum surface undulations of less than 3 $\mathrm{nm}$, for which a representative film is shown in Fig. 1(a). At and above a $\mathrm{N}$ content of 14 at. $\%$, the surface texturing that takes place is shown in Fig. 1(b). This was deposited with a $\mathrm{N}$ content of 15 at. $\%$. The nodulelike structures grow radially with time and coalesce with each other at a vertical growth rate of $\sim 0.25 \mathrm{~nm} / \mathrm{s}$. Reasons as to the abrupt change in structure from smooth amorphous to nodulelike amorphous films is unclear at present. When these films are examined under a scanning transmission electron microscope or transmission electron microscope, both the amorphous nature of the films and the textured nature of the films with the apparent boundaries between nodules is clearly visible.

Lifshitz et al. ${ }^{17}$ found that the surface morphology of their ion-beam-deposited $a-\mathrm{C}$ films was controlled by the ion energy of the $\mathrm{C}^{+}$, which in turn controlled the $s p^{2}$ fraction in their films. The nominally smooth, high $s p^{3}$ content films became more and more textured as the graphitic, i.e., $s p^{2}$, content increased. In the $a-\mathrm{C}: \mathrm{H}: \mathrm{N}$ films grown in this study, 


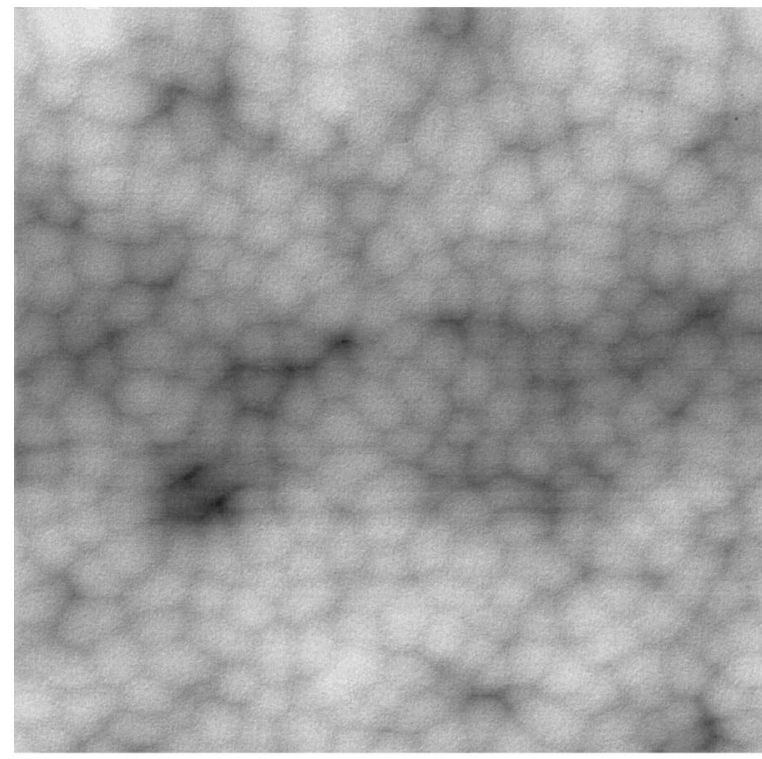

(a)

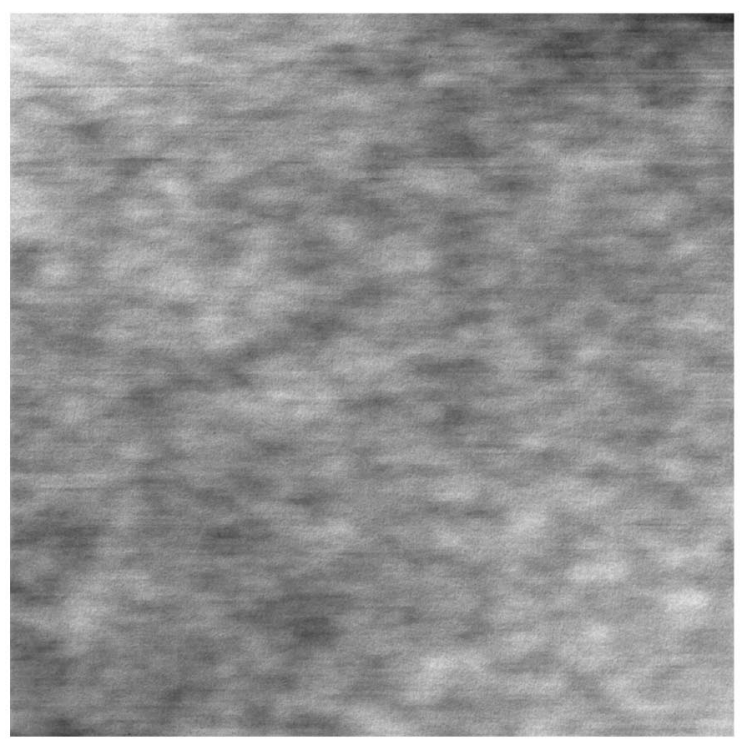

(b)

FIG. 1. The variation in the surface morphology for an $a-\mathrm{C}: \mathrm{H}: \mathrm{N}$ thin film using atomic force microscopy from a film with (a) 11 at. \%, and (b) 15 at. $\%$ nitrogen. Both figures show a scan area of $1 \mu \mathrm{m} \times 1 \mu \mathrm{m}$.

a C $s p^{2}$ content of $62 \%$ and $75 \%$ and a $\mathrm{N} s p^{2}$ content of $30 \%$ and $90 \%$ was measured for the films with 11 and 15 at. $\% \mathrm{~N}$, respectively. ${ }^{16}$ All the films in this study were deposited under very similar conditions (i.e., the same dc selfbias voltage and pressure in the rf PECVD process) on substrates held at room temperature. Therefore, the change in texture cannot be attributed to either the ion energy of the $\mathrm{CH}$ ion species or the substrate temperature. The change in structure of the films is, therefore, related to the bonded $\mathrm{N}$ content. As the films with the higher concentration of $\mathrm{N}$ have a larger percentage of $\mathrm{C} \pi$ bonds, this could lead to an increase in the $\mathrm{C} s p^{2}$ content. It may also suggests that nitrogenation leads to triple bonded $\mathrm{C}=\mathrm{N}$ sites.

The $J-E$ characteristics shown in Fig. 2 are for films deposited with a $\mathrm{N}$ contents of 11 and 15 at. \%. It is clear
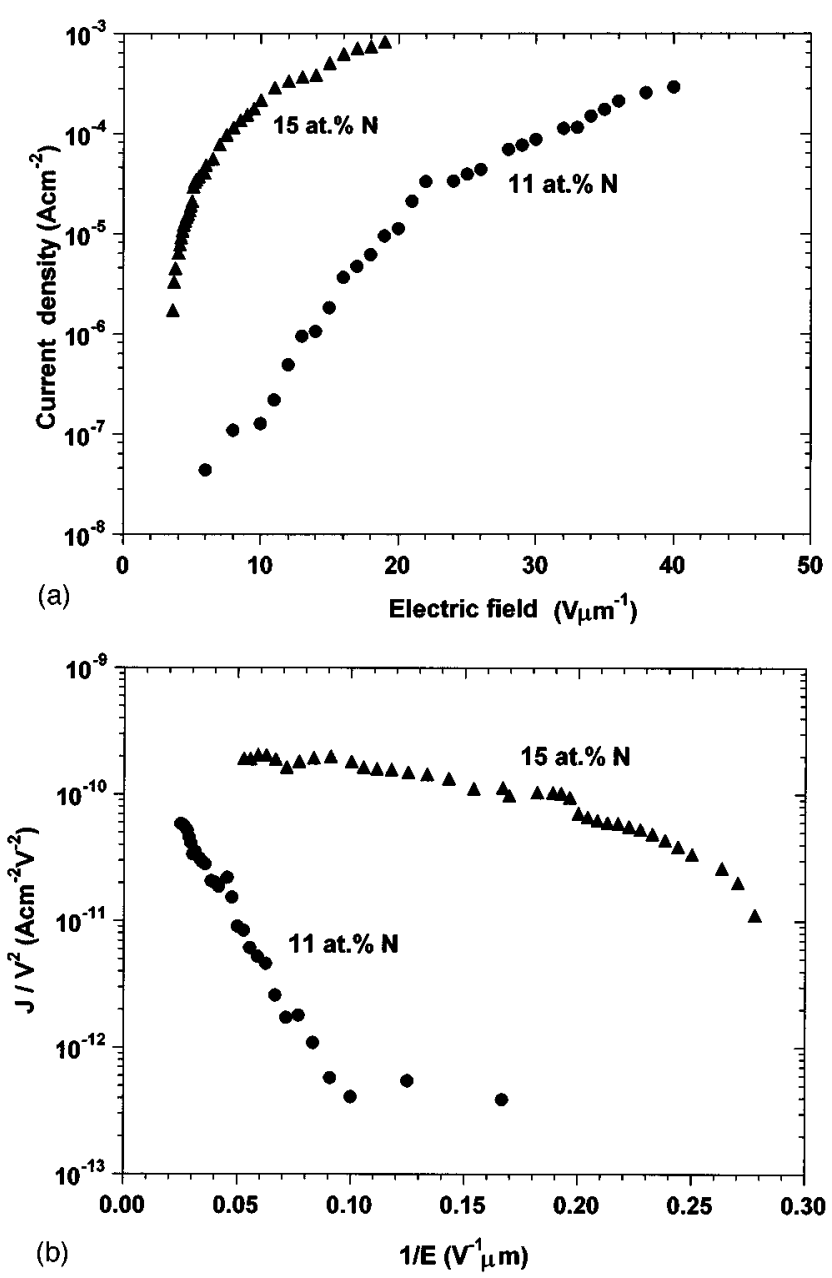

FIG. 2. The variation of the (a) current density $(J)$ versus electric field $(E)$, and (b) the corresponding Fowler-Nordheim plot for the $a-\mathrm{C}: \mathrm{H}: \mathrm{N}$ thin films.

from Fig. 2(a) that the film with the higher $\mathrm{N}$ content shows a marked improvement in the current-density versus electricfield characteristics, with a lower threshold electric field for current emission in the region of $5 \mathrm{~V} / \mu \mathrm{m}$. The current density, $J$, in the emission has a close $E^{2}$ dependence, which may indicate that space-charge-limited current conduction takes place within the $a-\mathrm{C}: \mathrm{H}: \mathrm{N}$ films. For the current to be space-charge limited in the vacuum, it should follow a Langmuir-Child's law, which would give a current density, $J$, dependence of $E^{1.5}$ For the current to be space-charge limited in vacuum, very high current densities are required, whereas space-charge-limited current in insulators/semiinsulators and defective insulators at low current densities is quite common. ${ }^{18}$ Undoped $a-\mathrm{C}: \mathrm{H}$ films have shown spacecharge-limited current in previous studies. ${ }^{19}$

The Fowler-Nordheim $(\mathrm{F}-\mathrm{N})$ plots that are applicable when electron emission into vacuum takes place are shown in Fig. 2(b). Although, on initial inspection, it appears that the plotted data follow a Fowler-Nordheim-like characteristic, it is possible that the $J-E$ characteristics for these films are a mixture of space-charge-limited current within the bulk film accompanied by $\mathrm{F}-\mathrm{N}$-type emission from the film surface. It has been shown that $\mathrm{N}$ incorporated into $a$-C:H films acts as a weak donor state that moves the activation energy 
from $\sim 0.8$ to $\sim 0.5 \mathrm{eV}$ from the conduction-band edge for the $1.8-2.0 \mathrm{eV}$ band-gap films analyzed in this study. ${ }^{16}$ The conductivity of the $a-\mathrm{C}: \mathrm{H}: \mathrm{N}$ films is, therefore, still very low $\left(\sim 10^{-5} \Omega^{-1} \mathrm{~cm}^{-1}\right)$ at room temperature and cannot sustain a high conduction current through the film at low electric fields. However, since there is a weak doping effect, with the increased atomic $\mathrm{N}$ content in the films, it is more likely for there to be space-charge-induced band bending in the fully depleted $a-\mathrm{C}: \mathrm{H}: \mathrm{N}$ film due to an increased ionized donor concentration in the films due to the presence of the $n^{++}-\mathrm{Si} / a-\mathrm{C}: \mathrm{H}: \mathrm{N}$ heterojunction, as discussed previously. ${ }^{8}$ The fully depleted $a-\mathrm{C}: \mathrm{H}: \mathrm{N}$ thin films may cause the current to be space-charge limited, giving rise to the $J \alpha E^{2}$ relationship, when electron emission into the vacuum from the film surface is readily achieved.

A simplified Fowler-Nordheim equation ${ }^{1,20}$

$$
J=S \frac{1.54 \times 10^{2}(\beta V)^{2}}{\phi} \exp \left(\frac{-6.83 \times 10^{3} \phi^{3 / 2}}{\beta V}\right)
$$

and $\beta=R /[k r(R-r)]$, where $S$ is the fraction of area emitting electrons, $E=\beta V$ is the field in $\mathrm{V} / \mu \mathrm{m}, \beta$ is the field enhancement factor, $\phi$ is the effective work function in $\mathrm{eV}$, $R$ is the tip-to-anode spacing, $r$ is the tip radius, and $k$ is a constant; and $1<k<5 . k \sim 5$ for a distant anode. ${ }^{1}$ This gives an enhancement factor $\beta$ of $\sim 10$ for the $50 \mu \mathrm{m}$ anodecathode spacing and $r$ derived from the AFM measurements (Fig. 1).

There is an increase in the current density at fixed electric fields of over two orders of magnitude throughout the range measured. The Fowler-Nordheim plots, from both the $11 \%$ and $15 \% \mathrm{~N}$ in $a-\mathrm{C}: \mathrm{H}: \mathrm{N}$ films could at first sight be interpreted as field emission from the surface with different barriers, as indicated by the two different gradients of the two sets of data. The electric field used in plotting the data for Fig. 2(b) assumes an ideal thin film with an uncorrected $\beta$ factor of 1. Using this data, an electron barrier for emission of $\sim 0.04$ and $\sim 0.01 \mathrm{eV}$ is calculated for the two films with $\mathrm{N}$ contents of 11 and 15 at. $\%$, respectively. When the $\beta$ factor shown in Eq. (2) is taken into consideration in the Fowler-Nordheim plot for the film with the higher $\mathrm{N}$ content, a barrier for emission of $0.5 \mathrm{eV}$ is obtained (the barrier for the other "smooth" film remains unchanged). The $\beta$ factor obtained may account for an order of magnitude increase in the current density for the film with the higher $\mathrm{N}$ content, due to the affect of the field enhancement factor on the preexponential term in Eq. (1), but cannot account for the observed increase of over two orders in the current density. Additional increases in current density are likely to be related to the doping effect in the $a-\mathrm{C}: \mathrm{H}: \mathrm{N}$ films.

According to the work by Robertson et al. ${ }^{11}$ the electron affinity of the $a-\mathrm{C}: \mathrm{H}: \mathrm{N}$ films examined in this study should have a value close to $\sim 2 \mathrm{eV}$. This is clearly not the case according to the Fowler-Nordheim analysis of the electron barrier heights. Reasons as to the reduction in barrier height have been related to the fact that the electron emission observed is not purely due to classical Fowler-Nordheim-type emission, but to Fowler-Nordheim emission of hot electrons in the higher energy states of the conduction band induced by space-charge band bending. ${ }^{8}$ However, the ultralow emis- sion barrier of $0.04 \mathrm{eV}$ derived for the "smooth" film, $a-\mathrm{C}: \mathrm{H}$ (Ref. 12) and $a-\mathrm{C}: \mathrm{H}: \mathrm{N}$ (Ref. 8) compared to $0.5 \mathrm{eV}$ for the textured film, show that the hot electron emission model alone cannot account for the low barriers predicted by the $\mathrm{F}-\mathrm{N}$ curves.

It is interesting to note that both Fowler-Nordheim curves shown in Fig. 2(b) and those analyzed in Ref. 8 all intercepted the $J / V^{2}$ axis at a single point despite six different sets of samples being examined. This would correspond to an emission area of the order of $10^{-28}-10^{-29} \mathrm{~m}^{2}$ if we assume the $\beta$ factor to be one and $\phi$ to be $0.04 \mathrm{eV}$ for all the films analyzed. The actual $a-\mathrm{C}: \mathrm{H}: \mathrm{N}$ cathode area over which the emission was observed was $10^{-4} \mathrm{~m}^{2}$, at low electric fields. If we were to use the barrier height as $2 \mathrm{eV}$, then an emission area of $3 \times 10^{-7} \mathrm{~m}^{2}$ will result. This would mean an effective area of emission of $0.3 \%$ of the nominally flat cathode is emitting on average at all times.

In conclusion, it has been shown that a marked improvement in the emission properties of $a-\mathrm{C}: \mathrm{H}: \mathrm{N}$ films can be obtained by using self-textured films with $\mathrm{N}$ contents larger than $14 \%$ acting as large area cathodes. Emission is obtained at very low threshold fields comparable with the best results published to date using amorphous films. The self-texturing observed in the $a-\mathrm{C}: \mathrm{H}: \mathrm{N}$ films deposited with high $\mathrm{N}$ content is considered to be one possible route in producing cheap large area cathodes for flat panel displays.

The authors thank Dr. M. E. Welland of Cambridge University for providing the AFM facilities.

${ }^{1}$ I. Brodie, Proc. IEEE 82, 1006 (1994), and references therein.

${ }^{2}$ J. E. Jaskie, MRS Bull. 21, 59 (1996).

${ }^{3}$ M. W. Geis, J. A. Gregory, and B. B. Pate, IEEE Trans. Electron Devices 38, 619 (1991); M. W. Geis, J. C. Twichell, J. Macaulay, and K. Okano, Appl. Phys. Lett. 67, 1328 (1995).

${ }^{4}$ N. S. Xu, R. V. Latham, and Y. Tzeng, Electron. Lett. 29, 1596 (1993).

${ }^{5}$ K. Okano, S. Koizumi, S. R. P. Silva, and G. A. J. Amaratunga, Nature (London) 381, 140 (1996).

${ }^{6}$ M. W. Geis, J. C. Twichell, N. N. Efremow, K. Krohn, and T. M. Lyszczarz, Appl. Phys. Lett. 68, 2294 (1996).

${ }^{7}$ N. Kumar, H. R. Schmidit, M. H. Clark, A. Ross, B. Lin, L. Fredin, C. Xie, C. Hilbert, R. L. Fink, C. N. Potter, A. Krishannan, and D. Elchman, SID 94 Digest 43 (1994).

${ }^{8}$ G. A. J. Amaratunga and S. R. P. Silva, Appl. Phys. Lett. 68, 2529 (1996).

${ }^{9}$ F. J. Himpsel, J. A. Knapp, J. A. Van Vechten, and D. E. Eastman, Phys. Rev. B 20, 624 (1979).

${ }^{10}$ B. B. Pate, Surf. Sci. 165, 83 (1986).

${ }^{11}$ J. Robertson, S. R. P. Silva, G. A. J. Amaratunga, and W. I. Milne, Mater. Res. Soc. Symp. Proc. 423, 777 (1996).

${ }^{12}$ G. A. J. Amaratunga and S. R. P. Silva, J. Non-Cryst. Solids 198-200, 611 (1996)

${ }^{13}$ S. R. P. Silva, G. A. J. Amaratunga, and B. J. Sealy, presented at the International Conference on Metallurgical Coatings and Thin Films, San Diego, April 1996.

${ }^{14}$ E. I. Givargizov, V. V. Zhirnov, A. V. Kuznetsov, and P. S. Plekhanov, J. Vac. Sci. Technol. B 14, 2030 (1996).

${ }^{15}$ S. R. P. Silva, J. Robertson, Rusli, G. A. J. Amaratunga, and J. Schwan, Philos. Mag. B 74, 369 (1996).

${ }^{16}$ S. R. P. Silva, J. Robertson, G. A. J. Amaratunga, B. Rafferty, L. M. Brown, J. Schwan, D. F. Franceschini, and G. Mariotto, J. Appl. Phys. 81, 2626 (1997).

${ }^{17}$ Y. Lifshitz, G. D. Lempert, and E. Grossman, Phys. Rev. Lett. 72, 2753 (1994).

${ }^{18}$ M. A. Lampert and P. Mark, Current Injection in Solids (Academic, New York, 1970).

${ }^{19}$ S. R. P. Silva and G. A. J. Amaratunga, Thin Solid Films 253, 146 (1994).

${ }^{20}$ A. Van der Ziel, Solid State Physical Electronics (Prentice-Hall, Eaglewood Cliffs, NJ, 1966), p. 144. 